\title{
Education, gender revolution, and fertility recovery
}

\section{Gøsta Esping-Andersen*}

In the contributions in this volume, varying explanations are given for why increasing levels of education among women are paving the way for higher birth rates. While this debate will no doubt continue, I think we can all agree that each and every one of the arguments made here is valid.

Diego Ramiro-Fariñas and colleagues focus on labor market conditions. Very much echoing the current Spanish situation, they argue that unemployment and job mismatches tend to depress fertility, even though unemployment (but not the mismatch problem) is less likely to affect the highly educated than the less educated.

Wolfgang Lutz hones in on the opportunity costs associated with satisfying fertility targets by observing that multiple births among the highly educated means foregoing quite a lot of income and career mobility. These cost-benefit considerations will, however, vary, as they depend on individual values and preferences. As I will discuss below, I, too, am convinced that values may overdetermine how individuals conduct their cost-benefit calculus.

Maria Rita Testa, in contrast, argues that higher education enhances individuals' ability to meet settled fertility targets, which are centered around a preference for having two (or more) children across all social strata.

Meanwhile, Jan Van Bavel contends that in the coming cohorts of highly educated women, fertility will depend to a large extent on the characteristics of the men with whom these women choose to partner. He also notes that current trends suggest that highly educated women are more likely than less educated women to marry, which is in turn associated with higher fertility; and that a high family income potential is positively associated with fertility. Specifically, he argues that as women are expected to make increasingly large contributions to the family income, the childrearing skills and the attitudes toward family roles of potential male partners may become increasingly important mate selection criteria for women.

The overall aim is, of course, not to maximize fertility per se. I think that all of the contributors would agree with the notion that fertility is a welfare issue. This implies

\footnotetext{
${ }^{*}$ Gøsta Esping-Andersen, CPIS, Universitat Pompeu Fabra, Barcelona, Spain Email: gosta.esping@upf.edu
} 
that the core challenge is to enable people to have the number of children they want to have. Taken together, the arguments represented at the roundtable add up to a comprehensive explanatory catalog for why contemporary birth rates fall short of people's stated preferences.

My modest contribution is to take one step backward in an effort to create a theoretical framework that can simultaneously embrace and unify all of these valid explanations. My point of departure is equilibrium theory.

Equilibria are premised on normative expectations. They are endogenously self-reproducing across time as long as they are not disrupted by some (major) exogenous shock that fundamentally alters their core modus operandum (Durlauf 2001). Within a stable equilibrium, any given individual will know what to expect, and what is expected of him or her. A person's expectations may be modest or extravagant, but the life course scenario is quite predictable. However, under conditions of equilibrium rupture, stability and predictability give way to uncertainty; and, possibly, to heightened anxiety about what the future has in store.

A stable family equilibrium could be observed in the postwar era. A woman's place was in the home, and girls were raised to become homemakers. As Goldin (2006) has argued, this model was disrupted by a number of exogenous shocks, including birth control, new time-saving household technologies, and the surge in women's educational attainment. These developments spurred women to invest in labor market skills, and to take up employment. In other words, the changes in women's roles helped to erode the traditional family equilibrium, and these trends in turn altered people's expectations, and fueled uncertainty about gender roles.

My core thesis is that a return to fertility levels that are more aligned with people's preferences will require the consolidation of a new, "gender egalitarian" family equilibrium. As McDonald (2000; 2002) has argued, institutional adaptation in the form of reconciliation policies is needed to achieve such an equilibrium. But adaptation at the micro level of the partnership and day-to-day family life are also needed (Esping-Andersen and Billari 2015). In a gender egalitarian equilibrium, any given woman can expect that any given man will behave in a gender symmetric fashion. When this is the case, a woman can be far more confident that her career and her childbearing goals can be realized in tandem.

Using the example of fertility, these dynamics are depicted in Figure 1. At stage A, the dominant norm of family life remains very much the traditional housewifecum-male breadwinner arrangement (which, as long as it remains broadly accepted, will produce high fertility rates - and also more marriages and fewer divorces). Theoretically speaking, under such conditions, changes occur only if a society experiences exogenous shocks. As women's roles evolve, but partnerships and societal institutions fail to adequately adapt to these changes, we find ourselves moving into stage B; i.e., a situation of normative flux and confusion about which partnership and family life arrangements are seen as desirable and proper. A widely cited example of this stage is the "double shift" phenomenon, whereby even a wife who is employed outside the home is expected to do the lion's share of the housework and the child care. 
Figure 1:

The revolution in women's roles and fertility

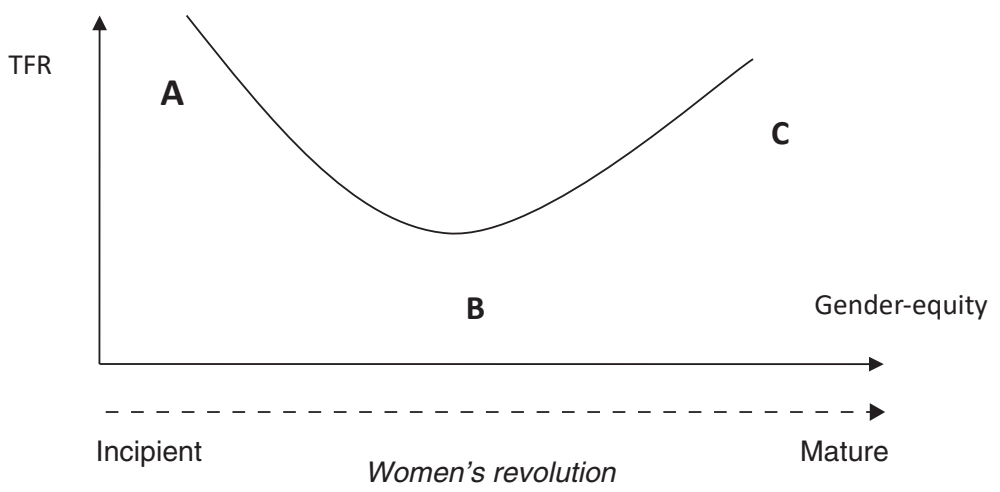

Economists would characterize stage B as a "multiple equilibrium" situation; i.e., a situation in which several and possibly contradictory normative guidelines co-exist. Under these circumstances, normative confusion is likely to prevail, and people are likely to be uncertain about what to expect. This confusion in turn weakens people's trust in their fellow citizens, and fuels their uncertainty about the future. There is strong empirical evidence that trust is a decisive precondition for partnering and having children (Aassve et al. 2012). In sum, fertility levels are likely to be low when the normative guidelines for family formation are unclear.

What would a new stable equilibrium (i.e., stage $C$ in Figure 1) look like, and what are the dynamics that would bring it about? The answer to the first question is quite straightforward: since the revolution in women's roles is irreversible (at least in the advanced democratic nations), it must clearly be founded on norms and practices that are genuinely gender symmetric. Only when such practices are broadly adopted and are socially accepted can we expect to see a return to pervasive trust and confidence in family life.

The answer to the second question is similarly straightforward: an acceleration of the diffusion of the new norms regarding gender roles and relations is needed. The news that the diffusion of egalitarian gender norms plays a central role in this process can be seen as positive. since people who are highly educated (and who are ideologically influential) are clearly the forerunners in this trend toward the adoption of new values.

I believe that the theoretical model I have sketched out here can be used to make sense of the rollercoaster ride that family life has been on over the past half century. This model can help us better understand why some societies (like the Nordic countries) have made far greater progress than others in moving in a more family-friendly direction. The populations of these countries tend to have more 
stable partnerships, and fertility levels that more closely match their preferences. ${ }^{1}$ In Scandinavia, both family life and public policy were adapted in response to the revolution in women's roles at an earlier stage, and to a far greater degree than in most other countries. To illustrate, the average Danish man does 41 percent of the housework in his family, and almost 30 percent of Danish men do more than 50 percent of the housework (Esping-Andersen et al. 2013). Thus, the Nordic countries have arguably entered stage C. In contrast, Germany, like Italy and Spain (among other countries), lag far behind in the adoption of gender symmetry in their welfare state policies and in their domestic spheres. These countries appear to be stuck in a (stage B) multiple equilibrium, in which normative uncertainty and confusion deter people from maximizing their welfare.

As we know, nothing is written in stone. As the American case suggests, the "gender revolution" may stall before it reaches full maturation (Cotter et al. 2011). We should also not forget that the Scandinavian path to gender egalitarianism is unique when viewed from an international perspective. In the Nordic countries, active family support policies were introduced at an early stage in the revolution in women's roles, and these policies were extraordinarily generous and comprehensive. The transformation in women's roles was no doubt eased by the plentiful supply of (more family-friendly) public sector jobs. Such conditions are almost non-existent not only in the US, but in much of Europe.

The equilibrium model also provides a clear rationale for why we should expect to observe higher fertility levels among more educated women. It is very clear that the highly educated strata are the vanguards of gender egalitarianism, just as they were the vanguards of fertility decline in the past. But we should also expect to see a gradual convergence across the social strata if and when the less educated are swept up by the diffusion dynamics of gender egalitarianism.

\section{References}

Aassve, A., Billari, F., and Pessin, L. 2012. Trust and family dynamics. Dondena Centre for Research on Family Dynamics Working Paper, no 55 (November).

Andersson, G. 2002. Fertility developments in Norway and Sweden since the early 1960s. Demographic Research 6: 67-86.

Cotter, D., Hermesen, J. and Vanneman, R. 2011. The end of the gender revolution? Gender role attitudes from 1977 to 2008. American Journal of Sociology 117: 259-289.

\footnotetext{
1 As we would expect, the U-shaped curve is more accentuated in some countries, and less so in others. Sweden is an example of the former case, arguably thanks to its early introduction of active family policies. If measured using the TFR, Swedish fertility was around 2.5 in the $1960 \mathrm{~s}$ (an era indisputably dominated by the traditional family model), declined to 1.6 in the late 1970s, and then recovered (with oscillations) to a level of around 1.9-2.0. A fairly similar profile emerges if we instead focus on fertility trends by birth orders (Andersson 2002).
} 
Durlauf, S. 2001. 'A framework for the study of individual behavior and social interaction'. Sociological Methodology 31: 47-87.

Esping-Andersen, G., D. Boertien, J. Bonke and P. Gracia 2013. A multiple equilibrium approach to couple specialization. European Sociological Review 29(4): 1280-1295.

Esping-Andersen, G. and Billari, F. 2015. Retheorizing family demographic change. Population and Development Review 41: 1-31.

Goldin, M. 2006. The quiet revolution that transformed women's employment, education, and family. American Economic Review 96(2): 1-21.

McDonald, Peter. 2000. Gender equity in theories of fertility transition. Population and Development Review 26(3): 427-39.

McDonald, Peter 2002. Low fertility: unifying the theory and the demography. Paper presented at Population Association of America Meetings, Atlanta, 9-11 May. 
